\title{
The Investigation of the Applicability of Fuzzy Rule-based Systems to Predict Economic Decision-Making
}

\author{
Anett Forgács ${ }^{1}$, Judit Lukács², Richárd Horváth² \\ ${ }^{1}$ Óbuda University, Doctoral School on Safety and Security Sciences, e-mail: \\ forgacs.anett@phd.uni-obuda \\ ${ }^{2}$ Óbuda University, Bánki Donát Faculty of Mechanical and Safety Engineering, \\ Népszínház u. 8, 1081 Budapest, Hungary, e-mail: lukacs.judit@uni-obuda.hu; \\ horvath.richard@uni-obuda.hu (corresponding author)
}

\begin{abstract}
Classical mathematics is the language of precision. Statements can be either true or false. But in our everyday lives and our systems (from economic behavior through social sciences to project management models, etc.), most things cannot be fully described by this logical concept. The solution to this problem might be the introduction of soft computing methods, especially Fuzzy logic. In this paper, a short review of the application of Fuzzy systems is presented from an economic perspective. In addition, the applicability of Fuzzy logic is demonstrated through a detailed example. In this part, the main goal is to select a target group of people for a new market campaign based on previously collected data. Qualitative and quantitative variables were used as well in the generated multi-input, singleoutput system. Finally, the evaluation process is discussed in detail to justify the conformity of the Fuzzy methodology.
\end{abstract}

Keywords: Fuzzy inference; soft computing methods; economic forecasts; decision-theory; risk analysis; behavior economics

\section{Introduction}

According to the classic approach of economic decision theory, human decisionmaking focuses on quantitative aspects in many areas. The starting point for this is that the products and services on the market are countable [1]. Smith and Taylor [2] also first examined the motivation and purpose with which participants engage in decision-making interactions in describing decision-making behavior. The principle that was formulated is the principle of utility. According to Smith [1], the process is about that the decision-maker usually has several alternatives. If these alternatives are implemented, some consequences or outcomes are reached, and each has a specific value and probability. The decision-maker has information about the 
available alternatives (input parameters) and their consequences (output parameters). The decision maker's ability to distinguish between alternatives is highly sensitive.

In many cases, in addition to the sensitivity of discriminatory ability, many theoretical variations can make it difficult to choose the right decision. This is indicated by the theory of bounded rationality [3], which considers that a person's ability to process information is limited in decision-making. The bounded rational decision-maker thus uses heuristics to help control the search for alternatives in a way in which we have a high chance to find a satisfactory solution. Furthermore, psychological approaches increase the relevance of subjective judgment compared to economic perceptions. That is fulfilled in three different ways [4]: on the one hand, it is crucial to capture why people do not make their risk decisions based on probabilities and expected values. On the other hand, the study has shown that if the decision is made based on quantified values, the probabilistic information, and thus the risks, are still incorrectly assessed. And finally according to the anthropological approach, in addition to social influences, the cultural background also plays an important role in determining uncertainty and thus in risk-taking and the resulting decision. Douglas and Wildavsky [5] found that people's reactions reflect their social position and opportunities to assert power.

Intuitive decision-making is a general phenomenon; the outcome of any decisionmaking process unfolds before the actual decision-making. Past experiences can have a substantial impact. Thus, the decision-maker can only be in balance with an intelligent device if the invisible model results in the least possible distortion. Previous experience and knowledge can be mapped to artificial working memory [6].

Szemere et al. [7] investigated the risk hierarchy. He found that the most critical risk in the investment process is the hedging of the investment. That is followed almost equally by the reliability of the collaborating contractor in the process. In third place, according to the sample issues, the quality of the work carried out and the flexibility of the project participants were set. The results showed that the availability of the parties involved in the process and the minimization of legal risks are essential aspects in implementing the project. These issues occupy the following two places. The return on investment risks are lower but rank high on the list of risk factors.

In some sectors, such as the banking sector, where risk assessment plays an outstanding role, more resources need to be invested in the development of compliance management systems, and it needs to be linked to organizational business processes. By integrating risk management and compliance management, the PRISM hybrid methodology provides a better and more accurate picture of risk assessment than the FMEA and RM methodologies alone when applying these systems. PRISM can be easily customized based on parameterization while focusing more on RPN values or partial risks [8]. 


\section{Theoretical Background}

The studies mentioned in the previous section revealed that several problems exist, which are difficult to handle with the help of classic mathematical principles. These are mainly rooted in algorithmic difficulties, lack of information, uncertainty, and vagueness. To solve this controversy, biologically inspired techniques were introduced. These spread away in any fields of investigations: engineering, system control, economics, decision support, etc. The three most commonly chosen concepts are Fuzzy systems, artificial neural networks, and genetic algorithms. In the case of Fuzzy inference, the main idea is to describe the way of human thinking and decision-making by extending the bivalent logic into a multivalued one, using transient phenomena (1965) [9]. Regarding artificial neural networks, their operation is based on the conduction process of the nervous system, including the learning process whose researching started in the 1940s [10]. Finally, a genetic algorithm is a kind of optimization technique suitable for searching a quasi-optimal solution based on the strain evolution and the inheritance of genetic traits (starting in the 1960s) [11]. These methods are also widely used in economic studies. For decision support, Fuzzy systems seem to be a promising solution. Several concepts were already provided in the case of modeling economic behavior and decision-making; their chronological order is the following.

Soft computing and Fuzzy methods can be used to make decisions and assess risks in many economic decisions. Ponsard has been addressing this issue since his work in 1980 [12]. In 1984 [13], he examined the conditions must be met for the compatibility of consumer and producer balances to be justified. For that purpose, a Fuzzy function and Fuzzy point set mapping was used. Furthermore, a comprehensive study was published on the same issues in 1988 regarding whether the effect of weaker rationality and the consequences of these decisions could be described in addition to the homo economicus model instead of the two precise positions [14]. In addition, three examples were presented to justify the usability of Fuzzy-based techniques: Fuzzy model of economic choice, economic calculations and economic equilibrium. In 1993, Dompere [15] introduced a method in which social or even project costs can be solved by Fuzzy decision theory, thus allowing, for example, optimal tax allocation or optimal allocation of project costs. Dompere [16] developed a comprehensive framework for social costing in cost-benefit analysis in his later work. From the elements in the cost identification matrix, the distributional weights of the cost burden were developed through Fuzzy-supported decisions and Fuzzy mathematical programming. An elaborative example of the theory's application to the problem of mental illness was presented in that study. In a later research on cost-benefit analysis, Dompere [17] showed that the distributional weights of benefit intensities are computed by the logic of the Fuzzy decision. Finally, a theory of efficient prices was presented [18] for cost-benefit analysis in the Fuzzy space - In this approach the proceeded by taking consumers' income and producers' outputs were posited as given. The working mechanism of the theory was illustrated by a computational example. At the same time, Escada et 
al. [19] presented the investigation project to develop an expert system for Demand forecast by Neuro-Fuzzy techniques. Their target was to study the feasibility of using Fuzzy neural networks and compare the results obtained from conventional tools. Lin [20] treated the optimal profit for Fuzzy demand in the Fuzzy sense.

Ganji et al. [21] presented a Fuzzy dynamic Nash game model of interactions between water users in a reservoir system. The model represented a Fuzzy stochastic non-cooperative game in which water users were grouped into four players, where each player chose its individual policies to maximize expected utility. According to their results, policy for each water user and the optimal policy of their reservoir system could be developed. Their proposed modeling procedures can be applied as an appropriate tool for reservoir operation, considering the interaction among the water users as well as the water users and reservoir operator. Aliev [22] argued that many economic dynamical systems naturally become Fuzzy due to uncertain initial conditions and parameters. An economic system was considered as a human-centric and imperfect information-based realistic multiagent system with Fuzzy logic-based representation. Fuzzy "if-then" knowledge and Fuzzy differential equations were used for modeling the economic agents. A behavioral model of agents was created using the Fuzzy and Bayes-Shortliffe approaches to incorporate motivation input variables of economic agents into their models.

Real options analysis is also a growing field of academic research and practical application because that is often difficult to understand and implement due to the complex mathematics involved. This problem can also be addressed by the softcomputing method of Collan et al. [23]. A new Fuzzy real option was presented as an evaluation method with Fuzzy numbers based on previous real option valuation methods and Fuzzy real options evaluation. That new method was also presented in an industrial setting. The results of this research field in recent decades were compiled by Shin and Wang [24]. They showed an overview of some of the basic mechanics of Fuzzy theory and current economic applications in both micro and macroeconomics.

The research and development ( $R \& D)$ project ranking as investments is a wellknown problem made difficult by incomplete and imprecise information about future project profitability. The Fuzzy technique can also be applied in this area, as demonstrated by Hassanzadeh et al. [25]. Their research aims to develop a practical research and development $(\mathrm{R} \& \mathrm{D})$ portfolio selection model that addresses the practical $R \& D$ project evaluation issue while tackling $R \& D$ uncertainty in portfolio optimization. Fuzzy set theory was employed to capture and model the uncertain project information. An example was also presented to compare these measures and illustrate the simplicity and applicability of the proposed approach. R\&D research also was investigated by Collan and Luuka [26]. Their work showed how can the evaluation of the profitability results of an R\&D project with Fuzzy method be ranked. They used four new variants of Fuzzy TOPSIS, each using a different Fuzzy 
similarity measure. The implementation of the created techniques was illustrated with a numerical example.

Another concerning economic research topic is the field of large industrial or gigainvestments because they are risky businesses with long economic lives that often control their markets. The information available is non-stochastic, normative, and often imprecise. Luuka and Collan [27] showed a new Fuzzy insurance pricing method for giga-investment project insurance. Their studies dealt with a new and intuitive four-step procedure for pricing giga-investment project insurance based on creating a pay-out distribution for the giga-investment project insurance contract. A numerical illustration of insurance pricing was also presented with the new method. On the other hand, the Fuzzy pay-off method was introduced profitability analysis tool. In this vein, their other work [28] analyzed the effect of the risk aversion in the possibilistic setting, relevant to giga-investments.

The application of a Fuzzy inference system to investment decision-support and real options analysis is a relatively new approach. Real options analysis looks at investment projects and assets as possibilities and analyzes their acquisition, project start, or making changes within projects as an option. Real options valuation is valuing these possibilities as options. Collan et al. [29] presented a new version of the Fuzzy pay-off method that incorporates a credibility measure into the real option valuation construct of the Fuzzy pay-off method. The real options analysis field was also studied with the Fuzzy method by Kozlova et al. [30]. They proposed a procedure for enriching investment and real options analysis performed with the Fuzzy pay-off method. Furthermore, based on the proposed procedure, a Fuzzy inference system was shown to support investment decision-making. The proposed procedure and the application of a Fuzzy inference system were illustrated with the numerical case analysis of a power generation investment. Related to this topic, Muzzioli and Baets [31] reviewed the literature that has addressed direct and inverse problems in option pricing in a Fuzzy setting then provided some lines for future research. Stokalsa et al. [32] presented the first fully probabilistic method for the real option valuation of investment projects, a new possibilistic variant of the Fuzzy pay-off method for real option valuation. The use of the new variant was illustrated with a set of numerical examples.

Ferrer-Comalat et al. [33] also proposed incorporating Fuzzy logic into the study of economic models. To develop this idea, they analyzed a simplified model for determining national income. It was assumed that set value is composed of consumption and investment for the sake of equilibrium. For gaining more objective information than that resulting from the application of classical models, they incorporated Fuzzy logic in their model.

The Fuzzy logic also offers a natural and convenient framework for modeling various concepts in social science. An example of this is found in their research by Ghosh et al. [34]. The level and spread of educational attainment and sustainable economic growth were examined by introducing the value of the education index. 
The results were in line with expectations, with the value of the Education Qualification Index rising with the better economic situation (in terms of employment, land value, household goods, livestock, etc.) and vice versa.

Based on the results of the different economic studies described above, covering a wide range of research areas -, it can be concluded that soft computing methods particularly Fuzzy logic and inference - provide promising results in economic decision-making and decision-support, social sciences, etc. In this paper, a multiinput, single-output (MISO) Fuzzy rule-based system is introduced. This example can be used as decision support. The presented model contains both types of independent variables: qualitative and quantitative ones as well. The estimated single dependent output variable shows the success of a market campaign, which can predict the target group in future problems. In this work, we basically emphasize the usability of the Fuzzy concept and its background rather than real case analysis.

\section{Methods}

In 1965, L. A. Zadeh [35] introduced the new methodology of Fuzzy sets. The aim was to provide a concept to solve problems previously addressed unsolvable within the framework of classic methods. The fundamental innovation was the simple modification in terms of the mathematical definition of sets. As a result, the strong boundaries were blurred, the membership function and the degree of membership were defined. The concept has been further developed, making it applicable in many areas, like decision-making problems [36] [37], modeling and control [38] [39] [40], practical analysis of systems [41], etc. [42].

The structure of a Fuzzy rule-based inference system is shown in Figure 1 that has four fundamental elements.

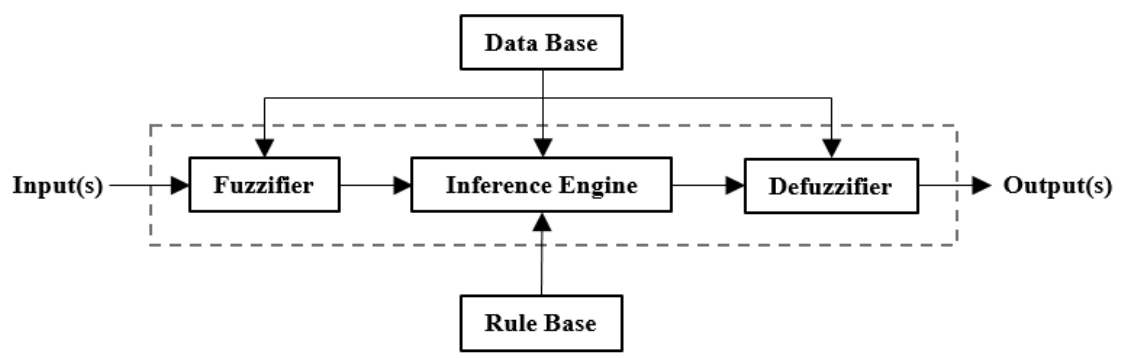

Figure 1

The structure of a Fuzzy inference system (based on [45])

The Fuzzifier is designed to describe the independent input and the dependent output variable(s) with the help of Fuzzy sets. There is the opportunity to use linguistic expressions and interval numbers instead of simple, crisp values in this 
step. The Rule Base is the storage box of the available expert knowledge concerning the specified problem. The Fuzzy rules are composed in IF ...(antecedent $(s)) \ldots$ THEN...(consequence $(s)) \ldots$ form and connect the input and the output variables. In the Inference Engine the rules are activated. The firing strength is defined by the membership degree of the independent variables, which is turned into the Fuzzy output set. More types of Fuzzy inference exist: the Mamdani-type [38] [39], the Sugeno-type [40], Tsukamoto-type [43], etc.

One of the most commonly used inference systems is the Mamdani type that describes expert knowledge based on previous information. The inference itself is introduced with the help of an example. Let us explain a simple system with two inputs $\left(x_{1}, x_{2}\right)$ and an output $(y)$ variable. The partition of the variables is shown in Figure 2.

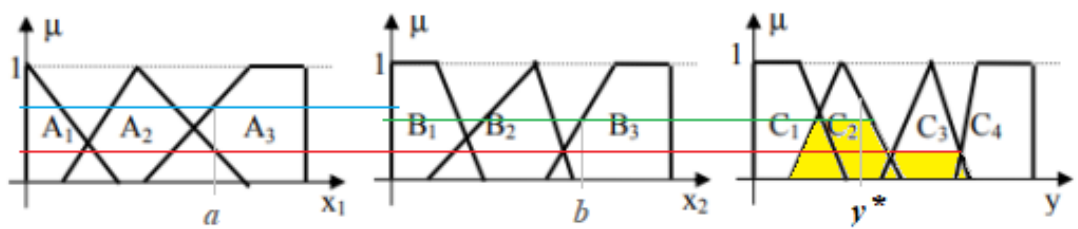

Figure 2

The Mamdani inference

In the case, when $x_{1}=a$ and $x_{2}=b$, two rules can be activated:

$$
\begin{aligned}
& R_{1}: \text { IF } x_{1}=A_{2} \text { AND } x_{2}=B_{3} \text { THEN } y=C_{3} \\
& R_{2} \text { : IF } x_{1}=A_{3} \text { AND } x_{2}=B_{3} \text { THEN } y=C_{2}
\end{aligned}
$$

In the case of Rule 1 (Eq. (1)), the membership degree of $a$ in $A_{2}$ is marked with a red line; the membership degree of $b$ in $B_{3}$ is marked with a green line. There is an $A N D$ connection between the conditions. As a result, the rule strength is the minimum of the membership values. So the activation level of $C_{3}$ is the red level.

On the other hand, Rule 2 (Eq. (2)) is activated as well. The membership degrees are shown with blue (in the case of $A_{3}$ ) and green (for $B_{3}$ ) lines. It can be said that the $A N D$ connection results in their minimum (the green level) as the firing strength of Rule 2. That becomes the level in $C_{2}$. Finally, the answer to the activated rules is the union of the results (the yellow area in Figure 2).

Finally, the resulting Fuzzy set needs to be transformed into a more tangible, more easily evaluated value. The Defuzzifier does this near to translation procedure. As it can be seen in Figure 2. the result is hard to understand. That is the reason why the defuzzification has to be carried out. So it is possible to get a more understandable output ( $y^{*}$ in Figure 2). Several defuzzification techniques exist, there is no general proposal on which concept to use. The best solution depends on the problem itself. 
Fuzzy inference systems might be a practical choice if uncertainty, lack of information, too many disturbances, or difficult-to-describe connection can be found around the investigated problem [42].

\section{Practical Example}

Our study examined a classic banking database for marketing purposes, originally uploaded to the UCI Machine Learning Repository. The dataset contains information about a financial institution's past telemarketing campaign pricing. The database they used (a Portuguese retail bank with data collected between 2008 and 2013) is freely available. Based on this, in 2014, Moro et al. [44] investigated which data mining methods (logistic regression, decision tree (DT), neural network $(\mathrm{NN})$, support vector machine) could be used to measure the prediction of a future successful telemarketing campaign, among which methods the neural network proved to be the most successful.

In this case study, we want to use Fuzzy's system for forecasting and decision preparation. For this goal we have analyzed the latest telemarketing campaign of the bank on which the database is based and filtered out the cases where the campaign was successful or unsuccessful. Then, we identified patterns that can be used to conclude future strategies to make future campaigns as successful as possible. The target group of our study was the entrepreneurs, mainly the corporate sector, and we looked at their forecasts for banking products.

\subsection{Structure of the Fuzzy Inference System}

Based on the available data, a MISO system is presented. The first step was selecting the variables. The significance test was carried out based on a statistical approach to determine the proper independent input parameters. It was revealed that the following variables have a significant effect: age, marriage, education, housing, loan. The single output was the success of the campaign. The main goal was to find out more target groups for similar problems in the future. For that purpose, a Mamdani type Fuzzy inference system was created. It can be said that a Mamdani type Fuzzy system can adequately describe databases containing expert knowledge. The structure of the system is shown in Figure 3.

The independent variables are either qualitative or quantitative ones. The precision and the flexibility of the system can be enhanced by using quantitative parameters. In this case, housing and loan were found to be qualitative ones. 


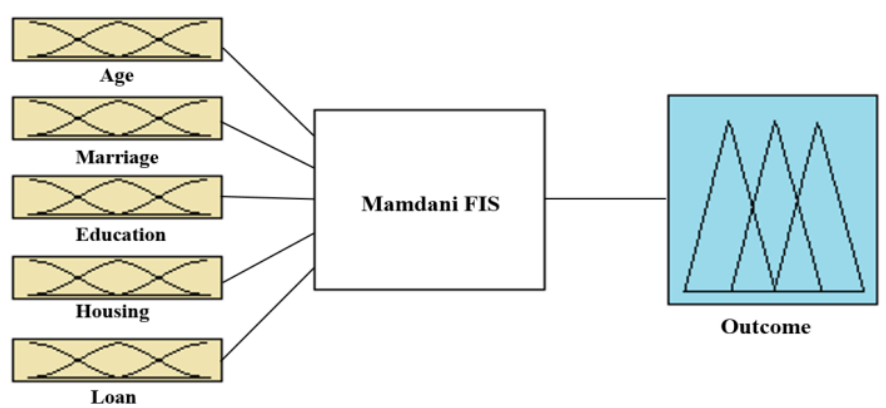

Figure 3

The structure of the FIS

Different types of membership functions were used to describe the partition of the input parameters: trapezoid (Eq. (3)), triangular-shaped (Eq. (4)), and the so-called Fuzzy singleton (Eq. (5)).

$$
\begin{aligned}
& \mu_{\text {trapezoid }}(x)=\left\{\begin{array}{ccc}
0, & \text { if } & x<a_{1} \\
\frac{x-a_{1}}{b_{1}-a_{1},} & \text { if } & a_{1} \leq x<b_{1} \\
1, & \text { if } & b_{1} \leq x \leq c_{1} \\
\frac{d_{1}-x}{c_{1}-d_{1},}, & \text { if } & c_{1}<x \leq d_{1} \\
0, & \text { if } & d_{1}<x
\end{array}\right. \\
& \mu_{\text {triangle }}(x)=\left\{\begin{array}{ccc}
0, & \text { if } & x<a_{2} \\
\frac{x-a_{2}}{b_{2}-a_{2}}, & \text { if } & a_{2} \leq x<b_{2} \\
\frac{c_{2}-x}{c_{2}-b_{2},} & \text { if } & b_{2} \leq x \leq c_{2} \\
0, & \text { if } & c_{2}<x
\end{array}\right. \\
& \mu_{\text {sglt }}(x)=\left\{\begin{array}{ccc}
1, & \text { if } \quad x=a_{3} \\
0, & \text { if } \quad x \neq a_{3}
\end{array}\right.
\end{aligned}
$$

where $a_{i}, b_{i}, c_{i}, d_{i}$ are the parameters of the membership function which can be used to tune the system.

The partitions of the independent variables are shown in Figure 4. In the case of age, the interval of $25 \ldots 65$ was investigated. Five different levels were determined (decennial breakdown, see Fig. 4a), which were characterized with the help of trapezoid membership functions. Regarding marriage, there are strict definitions of the different levels. However, there are transitional states; between single (0) and married (1), between married and divorced (2). As a result, the levels were described with triangular membership functions (see Fig. 4b). The same concept was used in the case of education; the levels were set from unknown (0), through primary (1) and secondary education (2) to the university degree (tertiary level, 3). 
The triangular-shaped membership functions are shown in Fig. 4c. Since it is harder to define transitions, housing and loan were found to be qualitative variables. The Fuzzy singleton function was used for their characterization (see Fig. 4d and e), which is similar to the characteristic function of a simple, crisp set. In these cases, the levels were either no (0) or yes (1).

Finally, Fig. $4 \mathrm{f}$ shows the partition of the single output variable. The outcome of the campaign described by the $0 \ldots 1$ interval, where 0 means the failure, 1 is the success. Triangular membership functions illustrate the levels. Based on Fig. 4f, it can be said that as the degree of failure decreases, an enhancement is in success, and the reverse is also true.

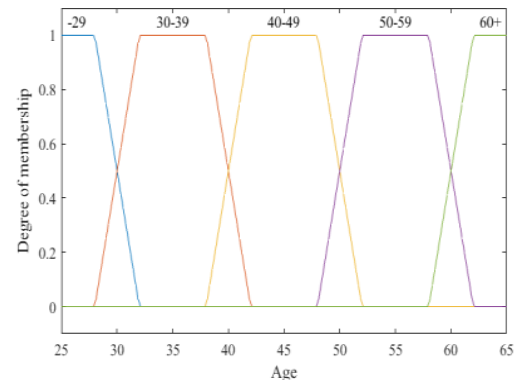

a) Membership functions of age

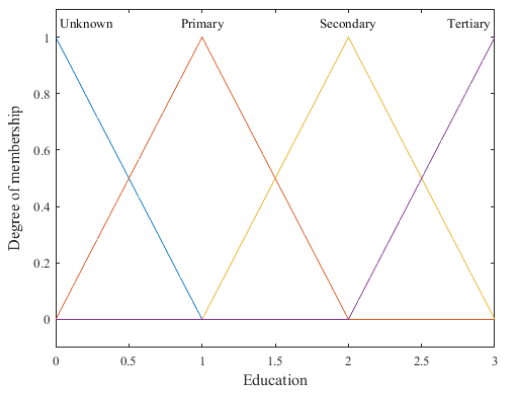

c) Membership functions of education

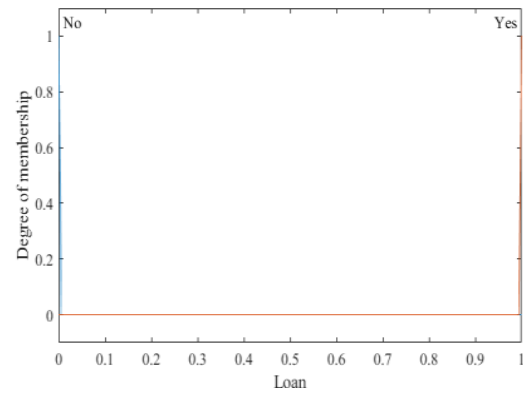

e) Membership functions of loan

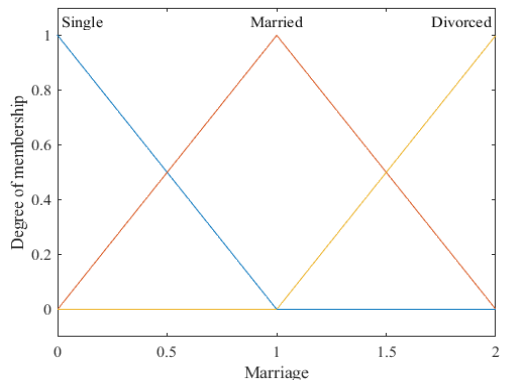

b) Membership functions of marriage

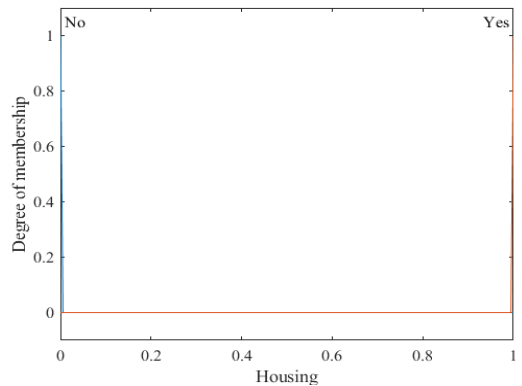

d) Membership functions of housing

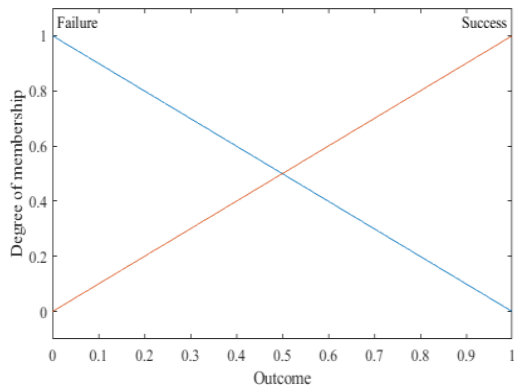

f) Membership functions of outcome

Figure 4

Partitions of the input and the output variables 
The connection between the independent input and the output variables is defined in the rule base. In this case, 34 combinations were used to train the system. These setting points are shown in Table 1.

Table 1

The rule base

\begin{tabular}{|c|c|c|c|c|c|c|c|}
\hline & & \multicolumn{5}{|c|}{ Inputs } & \multirow{2}{*}{\begin{tabular}{|c|} 
Output \\
Outcome
\end{tabular}} \\
\hline & Rule no. & Age & Marriage & Education & Housing & Loan & \\
\hline \multirow{34}{*}{ 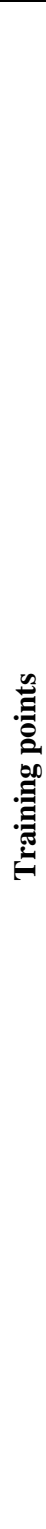 } & 1 & 26 & Single & Secondary & Yes & No & Failure \\
\hline & 2 & 29 & Single & Tertiary & Yes & No & Failure \\
\hline & 3 & 31 & Single & Secondary & Yes & No & Failure \\
\hline & 4 & 32 & Married & Secondary & No & No & Failure \\
\hline & 5 & 32 & Married & Unknown & Yes & No & Failure \\
\hline & 6 & 33 & Married & Secondary & Yes & No & Failure \\
\hline & 7 & 34 & Married & Tertiary & Yes & No & Failure \\
\hline & 8 & 35 & Married & Secondary & No & No & Failure \\
\hline & 9 & 36 & Divorced & Tertiary & No & No & Success \\
\hline & 10 & 36 & Single & Secondary & Yes & No & Failure \\
\hline & 11 & 36 & Married & Secondary & No & No & Failure \\
\hline & 12 & 36 & Single & Secondary & No & No & Failure \\
\hline & 13 & 38 & Married & Tertiary & Yes & No & Failure \\
\hline & 14 & 38 & Divorced & Secondary & Yes & No & Failure \\
\hline & 15 & 38 & Married & Tertiary & No & Yes & Failure \\
\hline & 16 & 39 & Married & Secondary & Yes & No & Failure \\
\hline & \begin{tabular}{|l|}
17 \\
\end{tabular} & 41 & Married & Tertiary & Yes & No & Failure \\
\hline & 18 & 42 & Married & Secondary & Yes & No & Failure \\
\hline & 19 & 44 & Married & Tertiary & No & No & Success \\
\hline & 20 & 44 & Single & Unknown & No & No & Failure \\
\hline & 21 & 44 & Married & Secondary & Yes & Yes & Failure \\
\hline & 22 & 44 & Married & Tertiary & Yes & No & Failure \\
\hline & 23 & 45 & Married & Secondary & No & Yes & Failure \\
\hline & 24 & 45 & Divorced & Tertiary & Yes & Yes & Failure \\
\hline & 25 & 46 & Married & Secondary & No & No & Failure \\
\hline & 26 & 47 & Married & Unknown & Yes & No & Failure \\
\hline & 27 & 49 & Married & Tertiary & Yes & No & Failure \\
\hline & 28 & 50 & Married & Primary & No & No & Failure \\
\hline & 29 & 51 & Divorced & Tertiary & No & No & Success \\
\hline & 30 & 52 & Single & Tertiary & Yes & No & Success \\
\hline & 31 & 56 & Divorced & Primary & No & No & Failure \\
\hline & 32 & 58 & Single & Primary & Yes & Yes & Failure \\
\hline & 33 & 59 & Single & Primary & Yes & No & Failure \\
\hline & 34 & 63 & Married & Secondary & No & No & Success \\
\hline
\end{tabular}


A Mamdani type inference system was generated with Largest of Maxima (LOM) defuzzification technique. The concept of LOM translation is shown in Figure 5.

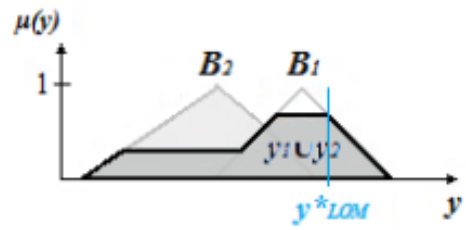

Figure 5

LOM defuzzification technique (based on [42])

\subsection{Evaluation}

The main goal of the evaluation procedure was to find possible target groups for future campaigns where a positive outcome can be expected. It was revealed that having a loan, housing, or both a profound impact on the negative outcome. In this section, the focus was on the opposite. As a result, the absence of these features was examined in the cases introduced below. The visualization of the outcome was done in three-dimensional space, so in each case one additional variable was kept constant.

Figure 6. shows the surface of the outcome plotted against the age and the marriage for participants who have completed secondary education. The promising results are shown with yellow color, and the poor success is marked with dark blue.

It can be demonstrated that even marital status and age have a considerable effect on the outcome. Two major target groups can be found in Figure 6. Focusing on singles, success can be achieved at $40 \ldots .50$ years old people. What is more, another possible target group was found in the case of the participants aged over 50, who are married. It is noted that these parameters need to be considered together.

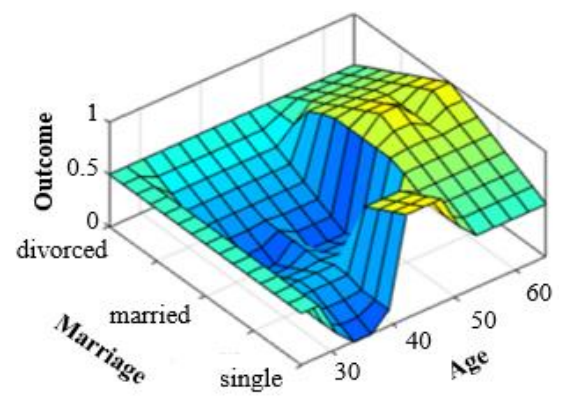

a) 3D surface plot

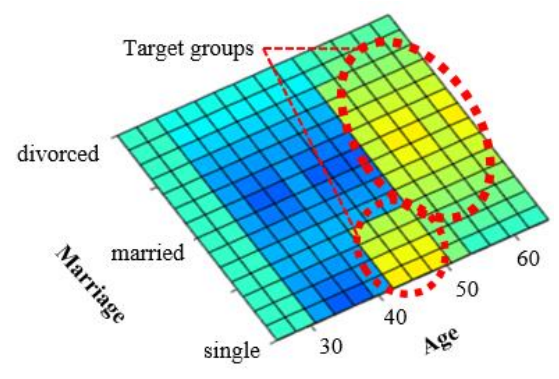

b) Contour plot

Figure 6

The outcome plotted against the age and the marriage (for secondary education) 
The effect of age and education on the outcome (see Figure 7) was investigated in the case of married attendees. In this case, it is convenient to focus on the group aged $40 \ldots 50$ with a university degree. Furthermore, corresponding to Figure 6 , for people over 50 years old, secondary education provides the most successful result.

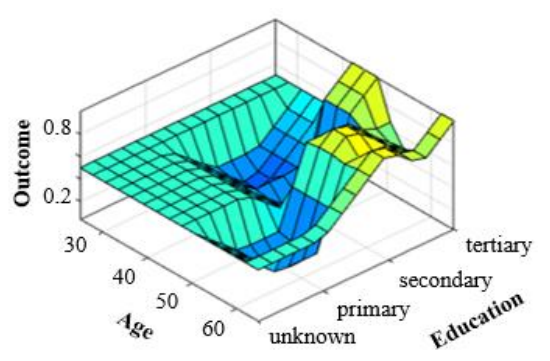

a) $3 \mathrm{D}$ surface plot

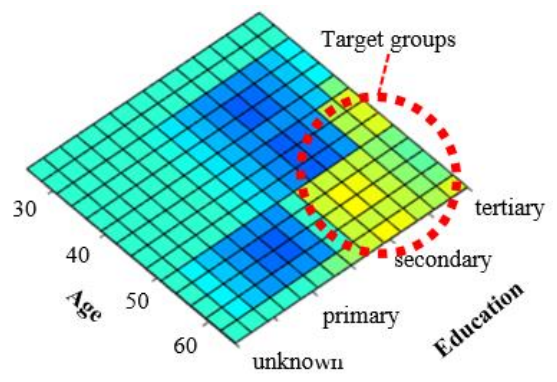

b) Contour plot

Figure 7

The outcome plotted against the age and the education (for married participants)

In Figure 8 the 45 years old category is analyzed, having no housing and no loan. It can be revealed that a forward-looking group is performed either by singles with a secondary degree or by marrieds with a university degree.

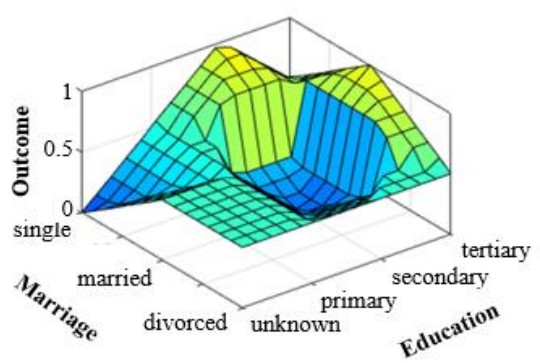

a) $3 \mathrm{D}$ surface plot

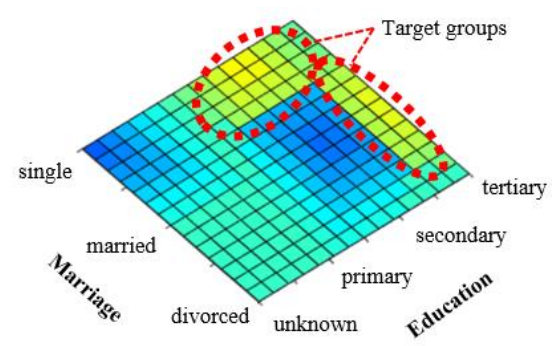

b) Contour plot

Figure 8

The outcome plotted against the marriage and the education (for 45 years old participants)

Finally, the age group of 55 years was investigated as well. Figure 9 shows the outcome plotted against the marriage and the education for this case. It was revealed that it is proposed to focus the campaign on married people with secondary schooling. Further contacted people might come from the tertiary-educated divorced attendees.

Overall, it can be concluded that having housing or loan or both worsen the success of the campaign. However, promising target groups of people can be chosen with the help of the Fuzzy inference system introduced above. 


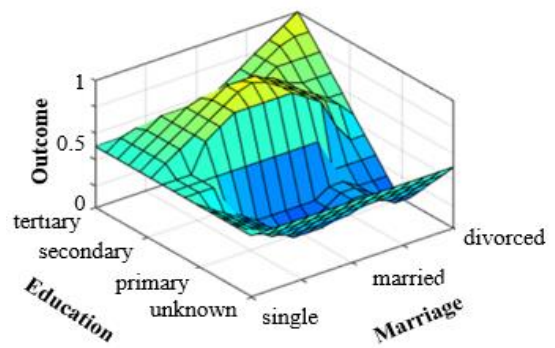

a) 3D surface plot

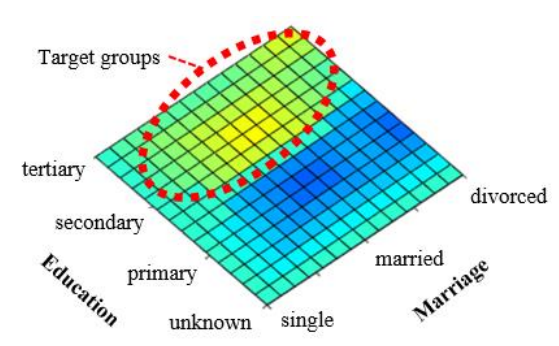

b) Contour plot

Figure 9

The outcome plotted against the marriage and the education (for 55 years old participants)

\subsection{Confirmation}

What is more, further testing points were chosen from the database used. These combinations were used to test the model and were not applied to train the system. The confirmation points are shown in Table 2. Regarding the predicted values over 0.7 can be considered to be successful. On the other hand, results under 0.3 are said to be undoubtedly a failure.

Table 2

Confirmation points

\begin{tabular}{|l|l|l|l|l|l|l|l|l|}
\hline & \multicolumn{7}{|c|}{ Inputs } & \multicolumn{2}{c|}{ Output } \\
\cline { 2 - 9 } No. & Age & Marriage & Education & Housing & Loan & Outcome & Predicted \\
\hline 1 & 31 & Married & Secondary & Yes & Yes & Failure & 0.125 \\
\hline 2 & 36 & Single & Tertiary & No & Yes & Success & 1 \\
\hline 3 & 38 & Single & Secondary & No & No & Failure & 0 \\
\hline 4 & 44 & Married & Secondary & Yes & No & Failure & 0 \\
\hline 5 & 49 & Single & Secondary & No & No & Success & 0.875 \\
\hline 6 & 54 & Divorced & Unknown & Yes & No & Failure & 0 \\
\hline 7 & 59 & Married & Secondary & No & No & Success & 0.875 \\
\hline 8 & 65 & Married & Tertiary & No & No & Success & 1 \\
\hline
\end{tabular}

It can be said that the results of the model correctly correspond to the measurement data in the cases of the training points. In addition, Table 2 shows that the system can be applied appropriately to estimate the outcome's success in those combinations that were not used during the training procedure. As a result, the Fuzzy inference system introduced above is suitable for defining future target groups. 


\section{Conclusion}

In this paper, some limitations of classic logic were presented with regards to economic aspects. Following the problem statement, several studies were given concerning the valuable opportunities provided by soft computing methods. Fuzzy logic was highlighted in particular for it was found to be a promising technique to support decision-making.

In addition, the applicability of the methodology was justified by a case study. In this section, a classic banking database was analyzed and used to generate a Mamdani type Fuzzy inference system. The aim was to provide some decision support in future market campaign strategies.

The following conclusions can be drawn:

- It was revealed that the introduced inference system could be used to find patterns. These results can be used to find target groups of people from whom success might be achieved in similar campaigns in the future.

- It can be said that the generated Fuzzy model was proved to follow the outcome derived from the data properly. For that purpose, besides the teaching point, further testing points were selected to confirm the accuracy of the model.

- It can be concluded that the Fuzzy system introduced accurately describes the available dataset (in the case of the teaching and the testing points as well). As a result, it can be used to support future strategies.

In the final conclusion, it can be drawn that Fuzzy systems are successfully applicable for decision support and solving further economic issues.

\section{References}

[1] Smith, A.:An inquiry into the nature and causes of the wealth of nations. Ed. RH Campbell, AS Skinner and WB Todd, 1776, Vol. 2

[2] Taylor, D. W.: Decision Making and Problem Solving. In.: Management Decision Making. Ed.: New York: Cyert-Welsh Penquin Books, 1970

[3] Simon, H. A.: Theories of bounded rationality. Decision and organization, 1972, No. 1(1), pp. 161-176

[4] Renn, O.: Concepts of risk: a classification. 1992

[5] Douglas, M.; Wildavsky, A.: Introduction: Can We Know The Risks We Face? University of California Press, In Risk and culture, 1983, pp. 1-15, https://doi.org/10.1525/9780520907393-002

[6] Velencei, J.; Szeghegyi, Á.; Baracskai, Z.; Andráskó, B. B.: Modeling the Intuitive Decision-Maker's Mindset. Acta Polytechnica Hungarica, 2019, Vol. 16, No. 3, pp. 227-240, https://doi.org/10.12700/APH.16.3.2019.3.12 
[7] Szemere, Tibor P.; Mónika Garai-Fodor.; Ágnes Csiszárik-Kocsir.:"Risk Approach-Risk Hierarchy or Construction Investment Risks in the Light of Interim Empiric Primary Research Conclusions", Risks, 2021, Vol. 9, No. 5, p. 84, https://doi.org/10.3390/risks9050084

[8] Bognár, F.; Benedek, P.: A Novel Risk Assessment Methodology: A Case Study of the PRISM Methodology in a Compliance Management Sensitive Sector. Acta Polytechnica Hungarica, 2021, Vol. 18, No. 7, https://doi.org/10.12700/APH.18.7.2021.7.5

[9] Zadeh, L. A.: Fuzzy sets. In Fuzzy sets, fuzzy logic, and fuzzy systems: selected papers by Lotfi A Zadeh, 1996, pp. 394-432

[10] Hebb, D. O.: The organisation of behaviour: a neuropsychological theory. New York: Science Editions, 1949, https://doi.org/10.2307/1418888

[11] Fogel, L. J.; Owens, A. J.; Walsh, M. J.: Artificial Intelligence through Simulated Evolution. New York: Wiley Publishing, 1966

[12] Ponsard, C.: Producer's spatial equilibrium with a fuzzy constraint. Doctoral dissertation, Institut de mathématiques économiques IME, 1980

[13] Ponsard, C.: A theory of spatial general equilibrium in a fuzzy economy. Institut de mathématiques économiques IME, 1985, p. 25

[14] Ponsard, C.: Fuzzy mathematical models in economics. Fuzzy Sets and Systems, 1988, Vol. 28, No. 3, pp. 273-283, https://doi.org/10.1016/01650114(88)90034-6

[15] Dompere, K. K.: The theory of fuzzy decisions, cost distribution principle in social choice and optimal tax distribution. Fuzzy sets and systems, 1993, Vol. 53, No. 3, pp. 253-273, https://doi.org/10.1016/0165-0114(93)90398-2

[16] Dompere, K. K.: The theory of social costs and costing for cost-benefit analysis in a fuzzy-decision space. Fuzzy Sets and Systems, 1995, Vol. 76, No. 1, pp. 1-24, https://doi.org/10.1016/0165-0114(94)00382-H

[17] Dompere, K. K.: Cost-benefit analysis, benefit accounting and fuzzy decisions.(I) Theory. Fuzzy sets and systems, 1997, Vol. 92, No. 3, pp. 275287, https://doi.org/10.1016/S0165-0114(96)00180-7

[18] Dompere, K. K.: The theory of approximate prices: Analytical foundations of experimental cost-benefit analysis in a fuzzy-decision space. Fuzzy sets and Systems, 1997, Vol. 87, No. 1, pp. 1-26, https://doi.org/10.1016/S01650114(96)00019-X

[19] Escoda, I.; Ortega, A.; Sanz, A.; Herms, A.: (1997, July). Demand forecast by neuro-fuzzy techniques. In Proceedings of $6^{\text {th }}$ International Fuzzy Systems Conference, 1997, Vol. 3, pp. 1381-1386, https://doi.org/10.1109/ FUZZY.1997.619745 
[20] Lin, D. C.: Optimal profit for fuzzy demand in the fuzzy sense. Journal of Interdisciplinary Mathematics, 2005, Vol. 8, No. 3, pp. 301-326, https://doi.org/10.1080/ 09720502.2005.10700410

[21] Ganji, A.; Khalili, D.; Karamouz, M.; Ponnambalam, K.; Javan, M.: A fuzzy stochastic dynamic Nash game analysis of policies for managing water allocation in a reservoir system. 2008, Water resources management, Vol. 22, No. 1, pp. 51-66, https://doi.org/10.1007/s11269-006-9143-y

[22] Aliev, R.: Decision analysis in fuzzy economics. The Caucasus \& Globalization, 2009, Vol. 3, No. 1, pp. 51-68

[23] Collan, M.; Fullér, R.; Mezei, J.: A fuzzy pay-off method for real option valuation. In 2009 International Conference on Business Intelligence and Financial Engineering, 2009, pp. 165-169, https://doi.org/10.1109/BIFE.2009.47

[24] Shin, C. Y.; Wang, P. P.: Economic applications of fuzzy subset theory and fuzzy logic: a brief survey. New Mathematics and Natural Computation, 2010, Vol. 6, No. 03, pp. 301-320, https://doi.org/10.1142/S1793005710001773

[25] Hassanzadeh, F.; Collan, M.; Modarres, M.: A practical approach to R\&D portfolio selection using the fuzzy pay-off method. IEEE Transactions on Fuzzy Systems, 2011, Vol. 20, No. 4, pp. 615-622, https://doi.org/10.1109/ TFUZZ.2011.2180380

[26] Collan, M.; Luukka, P. (2013) Evaluating R\&D projects as investments by using an overall ranking from four new fuzzy similarity measure-based TOPSIS variants. IEEE Transactions on Fuzzy Systems, 2013, Vol. 22, No. 3, pp. 505-515, https://doi.org/10.1109/TFUZZ.2013.2260758

[27] Luukka, P.; Collan, M.: New fuzzy insurance pricing method for gigainvestment project insurance. Insurance: Mathematics and Economics, 2015, Vol. 65, pp. 22-29, https://doi.org/10.1016/j.insmatheco.2015.08.002

[28] Collan, M.; Fedrizzi, M.; Luukka, P.: Possibilistic risk aversion in group decisions: Theory with application in the insurance of giga-investments valued through the fuzzy pay-off method. Soft Computing, Vol. 21, No. 15, pp. 4375-4386, https://doi.org/10.1007/s00500-016-2069-2

[29] Collan, M.; Fullér, R.; Mezei, J.: Credibilistic approach to the fuzzy pay-off method for real option analysis. Journal of Applied Operational Research, 2012, Vol. 4, No. 4, pp. 174-182

[30] Kozlova, M.; Collan, M.; Luukka, P.: New investment decision-making tool that combines a fuzzy inference system with real option analysis. Fuzzy Economic Review, 2018, Vol 23, No. 1, pp. 63-92, https://doi.org/10.25102/fer.2018.01.04 
[31] Muzzioli, S.; De Baets, B.: Fuzzy approaches to option price modeling. IEEE Transactions on Fuzzy Systems, 2016, Vol. 25, No. 2, pp. 392-401, https://doi.org/10.1109/TFUZZ.2016.2574906

[32] Stoklasa, J.; Luukka, P.; Collan, M.: Possibilistic fuzzy pay-off method for real option valuation with application to research and development investment analysis. Fuzzy Sets and Systems, 2021, No. 409, pp. 153-169, https://doi.org/10.1016/j.fss.2020.06.012

[33] Ferrer-Comalat, J. C.; Corominas-Coll, D.; Linares-Mustarós, S.: Fuzzy logic in economic models. Journal of Intelligent \& Fuzzy Systems, 2020, Vol. 38, No. 5, pp. 5333-5342, https://doi.org/10.3233/JIFS-179627

[34] Ghosh, I.; Ghosh, T. K.; Chatterjee, T.: A Fuzzy Logic-Based Mathematical Method for Measuring Educational Attainment

[35] Zadeh, L. A.: Fuzzy sets. In Fuzzy sets, fuzzy logic, and fuzzy systems: selected papers by Lotfi, 1996, pp. 394-432, https://doi.org/10.1142/2895

[36] Bellman, R. E.; Zadeh, L. A.: Decision-making in a fuzzy environment. Management science, 1970, Vol. 17, No. 4, p. B-141, https://doi.org/10.1287/ mnsc.17.4.B141

[37] Zimmermann, H. J.; Zysno, P.: Latent connectives in human decision making. Fuzzy sets and systems, 1980, Vol. 4, No. 1, pp. 37-51, https://doi.org/10.1016/0165-0114(80)90062-7

[38] Mamdani, E. H.: Application of fuzzy algorithms for control of simple dynamic plant. In Proceedings of the institution of electrical engineers, 1974, Vol. 121, No. 12, pp. 1585-1588, https://doi.org/10.1049/piee.1974.0328

[39] Mamdani, E. H.; Assilian, S.: An experiment in linguistic synthesis with a fuzzy logic controller. International journal of man-machine studies, 1975, Vol. 7, No. 1, pp. 1-13, https://doi.org/10.1016/S0020-7373(75)80002-2

[40] Sugeno, M.; Yasukawa, T.: A fuzzy-logic-based approach to qualitative modeling. IEEE Transactions on fuzzy systems, 1993, Vol. 1, No. 1, pp. 731, https://doi.org/10.1109/TFUZZ.1993.390281

[41] Zadeh, L. A.: Outline of a new approach to the analysis of complex systems and decision processes. IEEE Transactions on systems, Man, and Cybernetics, 1973, No. 1, pp. 28-44, https://doi.org/10.1109/TSMC.1973.5408575

[42] Ruspini, E.; Bonissone, P.; Pedrycz, W. (Eds.): Handbook of fuzzy computation. CRC Press., 2020, ISBN 978-0-7503-0427-6

[43] Tsukamoto, Y.: An approach to fuzzy reasoning method. Advances in Fuzzy Set Theory and Applications. 1979, pp. 137-149 
[44] Moro, S.; Cortez, P.; Rita, P.: A data-driven approach to predict the success of bank telemarketing. Decision Support Systems, 2014, No. 62, pp. 22-31, https://doi.org/10.1016/j.dss.2014.03.001

[45] Mallick, Z.; Kaleel, A. H.; Siddiqui, A. N.: An expert system for predicting the effects of noise pollution on grass trimming task using fuzzy modeling. International Journal of Applied Environmental Sciences, 2009, Vol. 4, No. 4, pp. 389-403 